\title{
Microfinance Training Services and Financial Sustainability of Small and Medium Enterprises in Kampala Central Division, Uganda
}

\author{
Henry Buwule Musoke (Ph.D.) \\ Ndejje University Graduate School, Kampala, Uganda. \\ hbuwule@gmail.com - hbuwule@ndejjeuniversity.ac.ug \\ https://orcid.org/0000-0003-4677-3474
}

Bukirwa Immaculate (MBA)

Banking Officer, Centenary Bank, Head Office: Mapeera House, Ghana.

immaculate.bukie@gmail.com

http://orcid.org/0000-0002-6245-5022

\begin{abstract}
The study investigated the effect of microfinance training services on the financial sustainability of Small and Medium Enterprises (SMEs) in Kampala Central Division. A correlational crosssectional survey design was employed. Data were collected using semi-structured questionnaires and interview guides from a sample of microfinance employees and SMEs entrepreneurs and employees. Data was analyzed using the narrative, descriptive, Pearson correlation, and linear regression analyses. Results indicate that microfinance training services affect financial sustainability of SMEs in Kampala Central Division. As the generator of new knowledge, training services must be placed within a broader strategic context of human resources management and must cover all areas of the business.
\end{abstract}

Keywords: Microfinance, microfinance training services, financial sustainability, small and medium enterprises.

\section{INTRODUCTION}

Small and Medium Enterprises (SMEs) in Uganda are in Business such as farming, buying produce, market vending, catering and confectionery, shop keeping, health services, stationary, manufacturing, among other service businesses. Many of these businesses start operations before acquiring licenses. They employ a minimum of 5 people and a maximum of over 100 people with relatively small working capital and income turnover. They are components of the informal sector that make up the national economy, since they operate with a low level of organization, low capital, low technology, and often temporary premises. Small and Medium Enterprises, are 
however, the drivers of economic development and job creation. This is because 90 percent of the economy is comprised of the private sector (Otage, 2014).

In Uganda, Small and Medium Enterprises contribute about 20\$ to GDP and employ about $90 \%$ of the non-farm economically active population (BoU, 2016; MFPED 2017). Approximately, there are 160000 Small and Medium Enterprises in Uganda employing about 2.5 million people (Mweheire 2018). Mweheire strongly believes that if we can enable each of the Small and Medium Enterprises to create additional four jobs, it would go a long way in solving the unemployment problem in Uganda. The Small and Medium Enterprises sector in Uganda is the most important area of the economy and economic growth will come from this area. If Small and Medium Enterprises are to continue employing the majority of Ugandans and contribute to GDP, they need to be financially sustainable.

Financial sustainability is a key dimension for Small and Medium Enterprises. It refers to the ability of Small and Medium Enterprises to cover their costs from their own generated income from operations. Financial sustainability centers on the ability of a Small and Medium Enterprise to depend on self-operations and imply the possibility of making a profit out of its operations. Financial sustainability implies that a loss-making Small and Medium Enterprise with poor financial performance cannot be classified as financially sustainable (Bukirwa, 2017). Unsustainable Small and Medium Enterprises will not contribute to the nation's GDP and ultimately will not create jobs. All the above factors show how indispensable the sustainability of Small and Medium Enterprises becomes imperative. Although many prior studies exist on Small and Medium Enterprises (e.g. Mulungi 2014), they were on other dimensions of performance and not financial sustainability. Therefore, the factors responsible for the financial sustainability of Small and Medium Enterprises in Uganda are not well known. Other studies were on other organizations that are listed on the exchange market with possibly extra regulations and on other variables.

Since Small and Medium Enterprises in Uganda are small businesses and whereas access to financing is one of the key issues faced by Ugandan businesses, there is a worry about the attrition rate of Uganda Small's and Medium Enterprises and the fact that less than 30 percent of them make it past their third birthday (Mweheire, 2018). This study was therefore, designed to investigate the influence of training services on the financial sustainability of Small and Medium Enterprises in Kampala Central Division, where most of these institutions are continuously formed and only survive for a short period (BoU, 2016)

\section{THEORETICAL FRAMEWORK}

The theory that underpinned this study is agency theory. Agency theory is concerned with resolving problems that can exist in agency relationships. That is, between principals (such as the owners) and agents of the principals, for example, managers (Bukirwa, 2017). The main objective of the agency theory is to structure the contractual relationship between the conflicting groups so that agents take actions to maximize the interests of the principals (Tiessen\& Water house, 1983).

In Small and Medium Enterprises, the principals (owners/ entrepreneurs) who have not involved in the day-to-day management of their businesses, delegate the management to agents (managers). The managers are supposed to run the Small and Medium Enterprises effectively and efficiently. However, due to the individualistic tendencies of the agents, the overall performance of these institutions may run down, which affects the Small and Medium Enterprises' performance and survival in the long run. The reasoning behind the agency theory is that, there exists a conflict of interest between the owners and management due to the existing gap between them and that, the extent of agency conflicts varies across the firms depending on the level of discretionary power applied by management (Mohiuddin \& Yusuf, 2010). For 
accountability purposes, management decisions and other organizational activities, there is a need to have close monitoring in Small and Medium Enterprises. The main issue in the agency theory is that, with close monitoring, the expert team (i.e. the employees of Small and Medium Enterprises) must exercise their expertise in the best interest of the Small and Medium Enterprises operational success. They must properly maximize the services of MFIs and other financial institutions from where they get financial services. We can, therefore, use agency theory to describe, explain, and predict financial sustainability of Small and Medium Enterprises.

\section{LITERATURE REVIEW}

\section{Financial Sustainability}

Small and Medium Enterprises need to operate sustainably if they are to achieve their objectives and produce impact. Sustainability necessitates profitability, financial prudence, purpose-driven management, and strategic governance. Financial sustainability is a key dimension of Small and Medium Enterprises. It refers to the ability of a Small and Medium Enterprise to cover all its costs from its own generated income from operations. All the definitions of financial sustainability center on the ability of a Small and Medium Enterprise to depend on self-operations and imply the possibility of making a profit out of its operations (Ganka, 2010). In this study, financial sustainability is initiated as operational sustainability and financial self-sufficiency. According to (Meyer 2002), operational sustainability refers to the ability of the Small and Medium Enterprise to cover its operational costs from its operating income. Small and Medium Enterprises are financially self-sufficient when; they are able to cover from their own generated income, both operating and financing costs. Financial sustainability implies that a loss-making small and Medium Enterprise with poor financial performance cannot be classified as financially sustainable.

Financial sustainability measures must focus their attention on what makes, identifies, and communicates the drivers of success. Financial performance measures are those which enable organizations to direct their actions towards achieving their strategic objectives because a firm's financial sustainability is central to the future well-being and prosperity of any enterprise (Kloot, 1999, Balunywa, 1999 and Dixon, Ritchie \& Siwale, 2006). Financial sustainability should be looked at in terms of the economy, efficiency, and effectiveness. Economy and efficiency are usually measured by financial terms like working capital, costs, volume of sales, and productivity. The economy is acquiring resources in appropriate quantities. Efficiency is maximizing inputs for a required output. Effectiveness is the extent at which the defined task has been accomplished which may be partly measured in terms of quality service, customers' satisfaction, and achievement of goals such as profitability (Bukirwa, 2017; Pandey, 1996; and Drucker, 1999). Firms cannot survive and prosper through their efforts. Each firm's sustainability depends upon the activities and performance of others, hence, the nature and quality of the direct and indirect relationship that a firm develops with its counterparts are fundamental (Hamel, 1991).

\section{Microfinance Institutions}

Microfinance is the provision of small scale financial services to low income or unbanked people (Hartarsaka, 2005). It is about the provision of a broad range of financial services such as savings, loans, payment services, money transfer, and insurance to the active poor and low-income households and their micro-enterprises. Microfinance Institutions are considered as tools for poverty alleviation that improve access to finance and financial services. They complement greatly the formal banking sector in providing financial services to the active poor (Basu Blavy \& Yulek, 2004). Microfinance Institutions (MFIs) have expanded the frontiers of institutional finance 
and have brought the poor into the formal systems by enabling them to access credit in order to fight poverty. Microfinance is seen to be an anti-poverty tool (Ahlin and Jiang, 2008).

Bank of Uganda defines MFIs as non-government institutions, Savings and Credit Cooperatives that provide savings and microloans to poor individuals, enterprises or groups for purpose of engaging in viable economic activities where there are difficulties in accessing financial services from the formal banking sector. Most formal financial institutions do not offer financial services to SMEs and poor households which justifies the existence of MFIs.

Far back in the 1970s, most developing countries including Uganda considered a capital investment to be a key factor in determining economic growth and rising incomes. This gave rise to MFIs becoming an important component of strategies designed to reduce poverty through the promotion of SMEs development.

Although large \& small enterprises have played a big role in Uganda's development and occupy an important place in promoting economic activities, their access to finance from financial institutions especially banks is still limited. This is because they lack collateral and they are vulnerable to economic changes amongst other reasons. (Michael, 2010).

The basic objectives of most MFIs established in developing countries are to alleviate poverty and promote self-empowerment of vulnerable and marginalized groups in the society such as small scale entrepreneurs by providing them access to financial services.

\section{Small and Medium Enterprises in Uganda}

Small and Medium Enterprises (SMEs) are the backbone of economies worldwide and Uganda is not an exception. They are key contributors to GDP, taxes, and employment. In Uganda, they employ about 2.5 million people, and the majority of who are youth. The government of Uganda supports SMEs through the Uganda Investment Authority (UIA) and the Ministry of Science, Technology, and Innovation. SMEs can help leverage and tap into the underutilized intraregional markets and trade.

As a nation, Uganda is a highly entrepreneurial country. The country has experienced a rise in the number of SMEs in different sectors. According to Uganda Investment Authority, SME Division, small enterprises are businesses that employ between 5 and 49 people and have total assets between shs 10 but not exceeding shs 100 million. The medium enterprise employs between 50 and 100 people with total assets more than shs 100 million but not exceeding shs 360 million Statistics from Ministry of Finance indicates that SMEs employ 2.5 million people where they account for approximately 90 percent of the entire private sector, generating more than 80 percent of manufactured outputs that contribute 20 percent of the Gross Domestic Product (GDP) (Ninsiima, 2019).

However, the statistics indicate that some SMEs fail to make five years in business and wither off. According to business experts, a number of mistakes attributed among others are; failure to handle customers properly; failure to create checks in managing human resource; poor handling of production processes; financing decisions, the ability to calculate the net profits and working capital; high appetite for artificial expansion, acquiring loans at the beginning of the business; high-interest rates on loans (the higher the interest rate, the lower the returns on capital employed); and lavish lifestyles (Murungi,2019). SMEs should know how to access different financing options and be able to ensure their business for better growth, learn how to file their taxes, and even get tax incentives. They should know how to keep books of accounts and corporate governance. SMEs should be able to license their businesses and enjoy government services, such as land in industrial parks and tax waives where applicable. All these can help them get joint ventures locally and internationally (Lyatuu, 2019). 
Uganda has a well regulated and highly liberalized economy in which all sectors are open for investment and, there is free movement of capital to and from the country. The government created a one-stop center for business registration and licensing at the UIA: The one-stop centre assists in tax advice and registration, immigration and work permit issues; land acquisition and verification, as well as environmental compliance and approaches. At the UIA, they hold investment conferences for technology innovations, business start-ups, and innovative SMEs. The aim is to sensitize SMEs and get into dialogue to get feedback for easing the business environment. UIA identify, nurture, mentor, and support competitive technological innovations, start-ups, and innovative SMEs in the country. They facilitate entrepreneurial and business skills training for Ugandan domestic investors to penetrate the market place.

The sustainability of SMEs depends on their ability to mobilize capital, access markets, possess the requisite business management skills and financial literacy. SMEs today are operating in an extraordinary business environment characterized by increasing globalization, heavy competition, newly empowered customers, and fast-changing technologies. To prepare for this new environment, SMEs need to transform themselves in fundamental ways by making major changes to their business models. In this respect, SMEs need their microfinance to assist in managing the uncertainties in their business; support their business expansion needs, and be there for them, not just in the good times.

In Uganda, according to report findings from the top 10 mid-sized companies study 2019, the majority of SMEs, still face slow loan payments, high taxes, and low working capital that hinders the sustainability of their business. SMEs should better their corporate governance and other aspects so that, they can be attractive for financing since microfinance and other financial institutions require certain things to be in place before they lend someone. They are operating on a global scale whereby, entities are looking at convenience and making business more efficient in the way they are growing. SMEs should access microfinance services most effectively and efficiently if they are to grow and remain sustainable. While there are several factors responsible for financial sustainability of small and Medium Enterprises in Uganda, the researchers were interested in investigating some of the microfinance services, where these institutions get financial services (e.g. credit, savings and training services) and how they influence their financial sustainability in Kampala Central Division, Uganda. This location was found to have the highest concentration of SMEs among the five divisions of Kampala. Also, the area had different types of SMEs including trading, service and manufacturing. Therefore, this made it easy for the researchers to access data in this area in terms of time and costs.

\section{Microfinance Training Services and Financial Sustainability}

Small and Medium Enterprises (SMEs) are increasingly taking the role of creating employment for the majority of Ugandans.

Microfinance is the provision of small scale financial services to low income or unbanked people (Hartarska, 2005). It is about the provision of a broad range of financial services such as deposits, loans, payment services, money transfers, etc. and other non-financial services such as training services, especially in business management. Microfinance institutions are considered as a tool for poverty alleviation through improving access to finance, financial services and other nonfinancial services. They complement effectively the formal banking sector in providing financial and non-financial services to the poor (Basu, Blavy\&Yulek, 2004).

Microfinance reduces poverty, which is considered as the most important development objective in international development frameworks. However, the positive impact of microfinance institutions on their clients including SMEs can only be realized, if the SMEs register good 
financial performance, that is, if SMEs are financially sustainable. They need to generate sufficient income to recover their operating costs and should depend on self-operations.

Small and medium enterprises continue to be formed in Kampala Central Division but survive for a short time (Bank of Uganda, 2016). While previous studies (e.g. Mulungi, 2014), documented poor performance of SMEs, especially their growth and profitability levels, none of them investigated the influence of non-financial services on the financial sustainability of SMEs. The factors affecting the financial sustainability of SMEs in Uganda are not known because; most of the previous studies were on microfinance services especially financial services and other performance measures and not financial sustainability. If SMEs are to stay in business for a long time and create employment for majority of Ugandans and also contribute to the development of the economy, then the factors affecting their financial sustainability must be identified.

Understanding the phenomenon of training and development requires an understanding of all the changes that take place as a result of improving the sources of any business. As the generator of new knowledge, training services are placed within a broader strategic context of human resources management, as planned staff education and development, both individuals and groups, within the goals to benefit both the organization and employees (Bukirwa, 2017). To preserve its obtained position and increase competitive advantage, the organization needs to be able to create new knowledge, and not only to solely rely on the utilization of the existing knowledge, thus, the continuous employee training and development have a significant role in the development of individuals and organizational performance.

One of the broad range of services that microfinance institutions offer to their clients (both individuals and businesses) is training services, especially in business management and entrepreneurial skills development, although it is not known whether these training services influence financial sustainability of businesses including SMEs. Beyond financial services, MFIs offer basic loan repayment training. Generally, the training is limited to emphasizing the importance of repaying the loan and of applying the loan to the business, rather than spending it on personal needs. These training services are believed to be strong correlates of financial sustainability of especially SMEs through the wise and successful use of savings and credit. (Bukirwa, 2017).

From the above discussion, it is evident that microfinance training services have a positive effect on financial sustainability of SMEs, because through training the SMEs on how they can save or use the credit facilities, it can help them to improve on their business growth and consequently their financial sustainability. However, most of the MFI training services center on the importance of repaying loans and of applying the loans to their businesses, rather than spending money on personal needs. Clients often face health emergencies and family crises. They also want to spend some of the loan proceeds on the education of their children which might not help their businesses to generate enough profit and grow. Microfinance needs to give SMEs more training in financial literacy and money management so that they can better meet both their business and personal needs, grow, and consequently become financially sustainable. This study was interested to investigate the influence of non-financial services (training services) on the financial sustainability of SMEs in Kampala, Central Division.

Drawing from previous studies, the independent variable in this study was microfinance training services given to SMEs, operationalized by such variables as the nature of the training and whether the training covers all the areas of business management and the breadth and depth of coverage. All these were assumed to influence the financial sustainability of SMEs. The dependent variable in this study is the financial sustainability of SMEs and was measured in terms of operational efficiency (the ability of SMEs to generate income out of their operations) 
and financial self-sufficiency (when an enterprise can cover from their own generated income, both operating and financing costs).

\section{METHODOLOGY}

\section{Research Design}

The study adopted a correlational cross-sectional descriptive survey research design. The correlational design was used because: the problem in this study was mainly identifying the influence of microfinance credit services on financial sustainability of Small and Medium Enterprises. The study used a cross-sectional design also known as single-short, because of the need to collect data at a single point in time. The cross-sectional design did not necessitate the researchers to make a follow-up on respondents. It was thus, used on account of its rapid turnaround in data collection as Creswell (2003) advises. Descriptive design was used to obtain information concerning the current status of the phenomenon to describe "what exists" with respect to variables.

The survey design enabled the collection of data from a large number of respondents. Surveys are also amenable to rapid statistical analysis and comparatively easy to administer and manage (Ahuja, 2005 \& Shajahan, 2005). The study also used both qualitative and quantitative data collection methods. A Qualitative data collection method was used because it helped the researchers to study variation of complex, human behavior in context and quantitative data collection methods were used because they allow for a broader study involving a greater number of subjects and entrusting the generalization of the results.

\section{Study Area and Population}

This study was conducted in Kampala Central Division district, Uganda. The area composed of many different types of SMEs, including retail, manufacturing, restaurants, wholesalers, etc, which were beneficiaries of Pride microfinance services. It was also convenient on part of the researchers to collect data, especially in terms of costs and time involved. The study population comprised of SMEs owners and employees, pride microfinance managers, and employees. SME owners and employees were involved because they are involved in the day to day activities of SMEs which access microfinance credit services. Managers and employees of the MFI were involved because of their information about credit services that the MFI gives to the SMEs and implement a variety of MFIs activities. However, due to time, costs, and other constraints, the researchers found it more convenient to carry out the study on part of the target population which was more accessible hence became their sampled population.

\section{Study Sample}

The study sample included owners and employees of selected SMEs and managers, together with employees of pride microfinance institutions. All these groups of respondents were aware of Small and Medium Enterprises, activities, and the microfinance credit services.

\section{Sampling Design}

Since the sample had many categories, namely; owners and employees from the different SMEs and managers and employees of the MFI, the sampling design combined purposive sampling from categories and random sampling within the categories.

\section{Sampling Procedures}


To attain the respective sample size from the population, the target population was divided into categories using stratified sampling technique to ease the collection of relevant data from each category most efficiently and effectively (American statistical association, 1999), taking into consideration the heterogeneous nature of the population to be sampled (Amin, 2005). Then a number of sampling methods were utilized as follows to select the sample from each category: for owners/entrepreneurs of SMEs and managers, credit officers and other key informants of pride MFI, a purposive method was used on account of their knowledge concerning the operation of their enterprises and MFI, respectively. Employees of Small and Medium Enterprises were selected using the simple random sampling method with the aid of sampling frames at Small and Medium Enterprises. This was on account that every respondent gets an equal chance of being selected to participate in the study. Small and Medium Enterprises were randomly selected from their groups.

\section{Sample Size}

The researchers used the Table developed by Krejcie and Morgan (1970) to determine the sample size from every stratum. According to that Table, for the 10 managers, 20 credit officers, and 10 other pride MFI, key employees, and for the 160 owners and employees (80 owners and 80 employees) of Small and Medium Enterprises, the required minimum samples were 10, 19, 10 and 113 , respectively.

\section{Data Collection}

Data was collected from both primary sources (by administering of questionnaires and interviewing key informants) and from secondary sources (by reviewing of relevant written documents at Small and Medium Enterprises and the MFI and others such as textbooks, journals, etc) self-administered questionnaires and the interview guide was utilized as the main data collection instruments. The validity and reliability of instruments were taken care of. Validity was determined using content validity index which was 0.813 and was above 0.7 as recommended by (Amin, 2005). The Cronbach's Alpha coefficient reliability method was applied from SPSS and was found to be 0.79. Again, according to Amin (2005), if the reliability is 0.7 and above, then the questionnaire is considered to be reliable for research.

\section{Data Processing and Analysis}

The researchers used the computer for data entry, cleaning, editing, coding and summarization to ascertain the accuracy, consistency, universality, proper arrangement and completeness of the data. After capturing the information, it was analyzed using SPSS, version 16, to summarize data into frequency tables. Descriptive statistics, Pearson correlation and regression analysis were utilized to describe the variables, to determine the associative relationship as well as the influence of MFIs training services on financial sustainability of Small and Medium Enterprises, respectively.

\section{FINDINGS}

The findings are presented in line with the objective of the study. According to the study, the independent variable is MFI training services. The dependent variable is financial sustainability of SMEs. In the next sub-sections, the summary descriptive statistics are given as well as the associative relationship and regression analysis 


\section{Descriptive Statistics}

Table 1: Description of Dependent variable (financial sustainability) and microfinance training services

\begin{tabular}{|l|l|l|}
\hline Variable & Mean & Standard deviation \\
\hline $\begin{array}{l}\text { Financial Sustainability } \\
\text { (Overall) }\end{array}$ & 2.91 & 0.541 \\
\hline $\begin{array}{l}\text { Microfinance training } \\
\text { Services }\end{array}$ & 2.93 & 0.594 \\
\hline
\end{tabular}

Table 1, shows that the overall on financial sustainability on a scale of 5 , respondents rated themselves low $($ Mean $=2.91$; S.D $=0.541)$ suggesting that financial sustainability in SMEs in Kampala Central division was low meaning that SMEs were probably not operationally sustainable. Further, descriptive statistics results in Table 1, indicate that overall respondents rated themselves low on all aspects of microfinance training services (Mean $=2.93$; S.D $=0.594$ ), suggesting that these trainings were probably not adequate to cover all areas of business management.

\section{Correlation Results}

Table 2; Correlation between microfinance training services and financial sustainability of SMEs

\begin{tabular}{|l|l|l|l|}
\hline & & $\begin{array}{l}\text { Microfinance Training } \\
\text { Services }\end{array}$ & $\begin{array}{l}\text { Financial } \\
\text { Sustainability }\end{array}$ \\
\hline $\begin{array}{l}\text { Microfinance } \\
\text { Training } \\
\text { Services }\end{array}$ & Person Correlation & 1 & $0.227^{* *}$ \\
\cline { 2 - 4 } & Sig(2-tailed) & & 0.007 \\
\cline { 2 - 4 } & $\mathrm{N}$ & & 142 \\
\hline \multirow{3}{*}{$\begin{array}{l}\text { Financial } \\
\text { Sustainability }\end{array}$} & Person Correlation & $0.227^{* *}$ & 1 \\
\cline { 2 - 4 } & Sig(2-tailed) & 0.007 & \\
\cline { 2 - 4 } & $\mathrm{N}$ & 142 & \\
\hline
\end{tabular}

** Correlation is significant at the 0.01 level (2-tailed)

Table 2, shows that there is a significant but weak positive associative relationship between microfinance training services and financial sustainability of SMEs $(r=0.227$; sig $=0.007)$ at the 0.01 level. The positive associative relationship, if predictive, suggests that when microfinance training services increase, the financial sustainability of SMEs also increases. However, there was a need to determine whether the relationship was predictive or not. This was done by running a simple regression analysis. The results are presented in Table 3. 


\section{Regression results}

Table 3; Simple regression results of microfinance training services and financial sustainability of SMEs

\begin{tabular}{|l|l|l|l|l|l|l|}
\hline \multicolumn{2}{|c|}{ Model } & $\begin{array}{l}\text { Sum of } \\
\text { Squares }\end{array}$ & Df & $\begin{array}{l}\text { Mean } \\
\text { Square }\end{array}$ & F & sig \\
\hline 1 & Regression & 268.304 & 1 & 268.304 & 7.596 & 0.007 \\
\hline & Residual & 4945.112 & 140 & 35.322 & & \\
\hline & Total & 5213.415 & 141 & & & \\
\hline
\end{tabular}

Predictors: (constant) MF training services

Adjusted R Square $=\mathbf{0 . 0 4 5}$

Dependent Variable: Financial Sustainability

Regression results in Table 3, show that MF training service aspects are collectively explanatory variables of financial sustainability of SMEs in Kampala Central Division ( $F=7.596$; sig = 0.007). However, MF training services only explain $4.5 \%$ of the variations in financial sustainability of SMEs (Adjusted R Square $=0.045$ ). This is also supported by the regression value of 268.304 compared to the residual value of 4945.112, suggesting that other factors strongly influence financial sustainability of SMEs in Kampala Central Division, other than MF training services. However, the study hypothesis that MF training services do not significantly influence financial sustainability of SMEs was rejected. There is a statistically significant influence of training services on financial sustainability of SMEs in Kampala Central Division. Findings concur with Bukirwa (2017) who affirms that, to preserve its obtained position and increase competitive advantage, the organization needs to be able to create new knowledge and not only solely rely on the utilization of the existing knowledge and that the continuous training has a significant role in the development of individuals and organizational performance. Training services however only explain $4.5 \%$ to variations in financial sustainability of SMEs, suggesting that as mentioned in the literature review, MF training is generally limited to emphasizing the importance of repaying the loan and of applying the loan to the business. Although such training is believed to be correlated with the financial sustainability of SMEs, the owners of these institutions often face family crises and spend the loan money on personal needs, which might not help their businesses to generate enough profit and grow. MF training services should cover other areas of business management in addition to financial literacy and money management.

\section{CONCLUSION AND RECOMMENDATIONS}

The objective of this study centered on investigating the influence of MF training services on financial sustainability of SMEs in Kampala Central Division. The study concludes that, MF training services are statistically influential factors of financial sustainability of SMEs in Kampala Central division. As the generator of new knowledge, training services must be placed within a broader strategic context of human resources management, that is, global organizational 
management, as planned structuring and development, benefit the organization and employees. This means further that MF training should cover all areas of business management.

Much as the study has contributed to the understanding of the influence of MF training services and financial sustainability of SMEs in Kampala Central Division, its findings should be used with caution due to the following limitations of the study. First, there were a few variables included in the model. It is not only MF training services that influence financial sustainability and financial sustainability but it can be measured at different levels other than operational efficiency and financial sufficiency. Secondly, the study is essentially a cross-sectional study that examined the influence of MF training services on financial sustainability of SMEs at a particular point. This may not give a complete picture of the phenomenon studied and may limit some of the conclusions obtained. Lastly, the nature of the sampling units under study cannot be generalized to a large population as only 80 SMEs and only in Kampala Central Division were examined. These were mainly urban SMEs. Majority of the SMEs including those in rural areas were not examined.

Considering the above limitations, therefore, the study opens up areas for further research. One, more variables should be included in the model; secondly, future studies may consider exploring appropriate econometric methods that improve the understanding of financial sustainability of SMEs. Thirdly, future studies should consider a large sample size for more accurate findings which are more generalizable nationwide. Lastly, future studies should extend the model to other organizations other than SMEs or other financial institutions services and how they influence financial sustainability of SMEs in Uganda and elsewhere.

\section{REFERENCES}

Ahlin, C., \& Jiang, N. (2008). "Can Micro-Credit bring Development", Journal of Development Economics, Vol. 86, pp. 2-25

Ahuja. R (2005), Research Methods, New Delhi Rawat Publications, Nice printing press,

American Statistical Association (1999) "Survey Research Methods Section Information. Htt://www.stat.nesu.educ/info/srms.html (accessed on 12 ${ }^{\text {th }}$ April 2013)

Amin, M.E (2005), Social Science Research: Concept, Methodology and Analysis: Makerere university printery, Kampala, Uganda

Balunywa, W. (1999). Creating Competitiveness in Uganda's Business. Discussion paper, Makerere University Business school

Bank of Uganda (2016).Financial Stability report, Issue No 8, June 2016

Basu, A., Blavy, R., \& Yulek, M. (2004). Microfinance in Africa: Experience and Lessons from selected African Countries: International Monetary Fund (IMF) Working Paper, NO WP/04/174

Bukirwa, I. (2017). Microfinance Institutions services and financial sustainability of small and Medium Enterprises in Uganda. Unpublished MBA, dissertation, Ndejje University, Kampala, Uganda.

Creswell, J.W (2003), Research Design qualitative, quantitative and mixed Methods approaches, (2 ${ }^{\text {nd }}$ edn), Thousand Oaks, SAGE, London

Dixon, R., Ritchie, J., \& Siwale, J. (2006). Microfinance: Accountability from the grassroots. Accounting, Auditing \& Accountability Journal, 3(9), 13-26 
Drucker, P. (1999). Management challenges of Business for the 21 st Century, New York, Harper Audio

Ganka, D.N. (2010). Financial Sustainability of Microfinance Institutions (MFIs) in Tanzania. PhD Thesis, University of Greenwich, UK

Hamel, G. (1991). Competition for competence and inter-partner learning within Ministry of Finance, planning and Economic Development report.

Hartarska, V. (2005). Governance and performance of microfinance institutions in Central and Eastern Europe and the newly independent states. World development, 33(10), 1627-1643.

Kloot, L. (1999). Performance measures in Small scale Enterprises

Krejcie and Morgan (1970), Determining sample size for research activities, Educational and psychological measurement 30608, SAGE Publications

Lyatuu, J. (2019 December 19). Uganda Investment Authority (UIA) gives lifeline to SMEs. The daily Monitor Pg 15

Meyer, R.L. (2002). The Demand for Flexible Microfinance Products: Lessons from Bangladesh, Journal of International Development 13

MFPED. (2017). Annual economic performance report 2016/17 Report (pp.1-40). Kampala, Uganda

Michael, O. (2010 January 26). Bank explosion a great chance for microfinance Institutions. The daily monitor P.14

Mohiuddin, M., \& Karbhari, Y. (2010). Audit committee effectiveness: A critical literature review. AIUB Journal of Business and Economics, 9(1), 97-125.

Mulungi, R. (2014). Microfinance and Growth of Small and Medium Enterprises in Uganda.Unpublished MBA Dissertation Ndejje University, Kampala, Uganda.

Murungi, P. (2019 December 19). Why some SMEs fail to succeed. The daily Monitor Pg 14

Mweheire, P. (2018 May 16-22). Stanbic Bank committed to improving Uganda's future. The observer P.24

Ninsiima, C. (2019 December 19). SMEs benefiting more from Top 100 survey. The daily Monitor $\operatorname{Pg} 13$

Otage, S. (2014 December 8). Small and Medium Enterprise Business. The monitor P.19

Pandey, I.M (1996). Financial Management, (7th Ed)., New Delhi, India; Vikas Publishing House PVT LTD

Shajahan. S (2005) Research Methods for Management (3 ${ }^{\text {rd }}$ edn) New Delhi Jaico Publishing House

Tiessen and Water house. (1983). Agency Costs, Theory of the Firm, Management Behavior and Ownership Structure: The Journal of Law and Economics, Vol 25

Yaron, T. (1996). Dynamics of Market share in the Microfinance industry in Bangladesh, MPRA Paper,Munnich, Germany.

Yunus, M. (2003). Group- based Savings and Credit for the Rural poor Economies. 